\title{
Uso da rede de serviços de Juiz de Fora: a opinião do usuário.
}

\section{Use of the health care net work of Juiz de Fora: the opinion of the user.}

Celia Regina Machado Saldanha*

\section{Resumo}

As mudanças no perfil demográfico e epidemiológico ocorridas nas últimas décadas adquirem características particulares no Brasil e impõem a redefinição das políticas públicas, em especial da saúde, o que culmina com a implantação da Estratégia de Saúde da Família (ESF) em 1994. Espera-se com essa estratégia uma mudança de paradigma, em que se faça valer os princípios do SUS de universalidade, eqüidade e integralidade por meio do cuidado continuado, da prevenção de agravos e da promoção da saúde, principalmente nas populações mais vulneráveis. Para funcionar dessa forma, porém, é necessária a existência de uma rede de serviços que garanta a assistência nos casos onde a ESF não consiga resolver, estabelecendo-se um fluxo de referência e contra-referência. Usando como método a entrevista não-estruturada aplicada em quatro unidades básicas de saúde funcionando com a ESF em regiões distintas de Juiz de Fora, nós nos propomos a discutir, a partir das percepções dos usuários inscritos no PSF, o funcionamento desta rede de serviços, em uma tentativa de encontrar alguns pontos de gargalo e propor estratégias que possibilitem melhorias no acesso do usuário.

\begin{abstract}
The demographic and epidemiological changes occurred over the last decades assume particular characteristics in Brazil and demand for a redefinition of public policies, in special as refers to the health policies. In 1994, this process culminates in the implantation of the Family Health Strategy (FHS) as a new paradigm following the basic principles of the Unified Health System, integrality, equity and universality, by means of continued care, disease prevention and health promotion principally for the more vulnerable populations. For meeting this demand, the strategy depends on a service network capable of delivering care in cases the FHS cannot resolve, establishing a reference and counter-reference system. Data were collected by means of semi-structured interviews in four basic healthcare units of the Family Health Program. Based on the view of the users enrolled in the Family Health Program we discuss the performance of this service network in an attempt to identify some bottlenecks and suggest strategies for granting better access to the users.
\end{abstract}

Palavras-chave: Saúde da família; Assistência à Saúde; Atenção Integral à Saúde.
Key Words: Family Health; Delivery of Health Care; Comprehensive Health Care.

*Mestre em Saúde da Família, Professora de Saúde Coletiva e Semiologia, Faculdade de Ciências Médicas e da Saúde de Juiz de Fora, Juiz de Fora, Minas Gerais, Brasil. 


\section{Introdução}

Mesmo os analistas mais pessimistas, ao analisar o desempenho do SUS (Sistema Único de Saúde), nas últimas décadas, admitem que houve avanços. Pudemos acompanhar as melhorias em relação à estrutura física, à incorporação de tecnologias aos diagnósticos e ao aumento importante dos serviços de Atenção Primária, na última década, com a implantação do Programa de Saúde de Família (PSF), mas há muito ainda por fazer pela saúde local.

O PSF permitiu, como estratégia estruturante do SUS, a oferta de serviços de saúde para segmentos da população que até bem pouco tempo não tinham acesso a quase nada, porém, ao se permitir a entrada no nível primário, obrigatoriamente, surge a demanda para que outros serviços estejam disponíveis, pois, uma vez feito o diagnóstico, precisamos continuar oferecendo cuidados para que a assistência se dê de forma completa. Essa demanda cria a imagem da rede de serviços, introduzindo a idéia da universalidade com equidade e integralidade ${ }^{1}$.

Autores renomados, como Starfield ${ }^{2}$ e Mattos ${ }^{3}$, reforçam a idéia de que, sem a integralidade das ações, a Atenção Primária não será resolutiva, e, embora bastante discutida e regulamentada por organismos mundiais ${ }^{4} \mathrm{em}$ leis e portarias federais ${ }^{5,6}$ - e nas propostas estaduais ${ }^{7}$-, alguns desafios ainda precisam ser vencidos, principalmente nos municípios, para alcançar as metas estabelecidas de saúde para todos.

Uma dessas portarias federais, o Plano Operacional de $1994^{6}$, norteou toda a implantação do PSF em Juiz de Fora, que, neste período, cresceu substancialmente e oferece hoje uma cobertura de mais de $50 \%$ da população de cerca de 500 mil habitantes, porém, algumas dificuldades ainda são percebidas na tentativa de reorientação do modelo assistencial local, para que se constitua a rede de servi$\operatorname{ços}^{7}$.

O objetivo desse estudo é analisar o quanto essas mudanças foram percebidas pelos usuários de unidades básicas com PSF, suas dificuldades na busca por assistência à saúde e como eles analisam a organização desses serviços.
Um dos requisitos para essa organização é a comunicação entre os setores, o que se constituiria uma rede de serviços, estabelecendo a integralidade. Segundo Starfield ${ }^{2}$ :

\begin{abstract}
A integralidade exige que a atenção primária reconbeça, adequadamente, a variedade completa de necessidades relacionadas à saúde do paciente e disponibilize os recursos para abordá-las. A decisão sobre quem deverá prestar cada tipo de serviço, se a atenção primária ou outro nivel de atenção, variam de lugar para lugar, de época para época, dependendo da natureza dos problemas de saúde de diferentes populações (p. 314).
\end{abstract}

Para contextualizar a importância da rede nos serviços de saúde, usamos como pano de fundo a transição demográfica, que é explicada pelo aumento da longevidade da população, e a transição epidemiológica, que é a diminuição das doenças infecto-contagiosas e aumento das crônico-degenerativas, embora esses processos tenham características especiais em países em desenvolvimento, como o Brasil - onde o aumento das doenças crônico-degenetativas ainda convive com muitas infecciosas, tendo inclusive o recrudescimento de algumas doenças que já eram consideradas sob controle, como a dengue e a febre amarela.

Apesar das doenças, estamos vivendo um momento de crescimento populacional que gera diferentes necessidades sociais e de saúde, o que impõe também "valorização dos diversos saberes e práticas na perspectiva de uma abordagem integral e resolutiva", além de "promoção e estímulo à participação da comunidade no controle social, no planejamento, na execução e avaliação das ações"

Tentar enxergar essa realidade sob o ponto de vista do usuário demonstra a necessidade de adequação do modelo assistencial em uma característica individualizada e, ao mesmo tempo, tão reprodutível em nosso país.

\section{Material e método}

Trata-se de um estudo de caso, de caráter qualitativo, realizado em quatro unidades de saúde de Juiz de 
Fora, em áreas geográficas distintas, norte, sul, leste e centro, todas funcionando com o Programa de Saúde da Família.

Foram entrevistados 32 pacientes, cadastrados no Sistema de Informação da Atenção Básica (SIAB), selecionados por sorteio aleatório, e que utilizavam o serviço regularmente.

As entrevistas foram previamente agendadas e realizadas nas unidades de saúde, utilizando-se como instrumento de coleta um roteiro de entrevista não-estruturado, permitindo que se manifestassem livremente a partir de perguntas simples usadas como provocação, não havendo o "cerceamento da fala dos entrevistados", e, como critério de suficiência da amostra, usou-se o da saturação, ou seja, o momento em que as respostas passam a se repetir ${ }^{8}$.

Todos os entrevistados aceitaram e assinaram um termo de consentimento livre e esclarecido.

Para análise dos conteúdos das entrevistas, usamos a leitura compreensiva exaustiva, procurando compreender, “além dos significados imediatos", para que pudéssemos ter a noção do conjunto com a compreensão das particularidades de cada fala, identificação dos temas mais citados, separação em categorias que permitissem agregar os valores referidos e a elaboração de síntese com articulação dos objetivos do estudo com a base teórica consultada?

Consultamos também os documentos oficiais do Sistema Único de Saúde (SUS), nos níveis federal e municipal, que se relacionavam à temática em questão para delinear o contexto do município e de suas políticas de saúde.

Antes de iniciarmos a pesquisa, o projeto foi submetido e aprovado pelo Comitê de Ética em Pesquisa com seres humanos da Universidade Estácio de Sá em cumprimento da Resolução 196/96 do Conselho Nacional de Saúde.

O foco de nosso estudo se deu nos aspectos subjetivos, considerando "a não-neutralidade do investigador ${ }^{10}$; a não-representatividade estatística das amostras selecionadas e a conseqüente impossibilidade de generalizar os resultados e replicar os estudos", mas, antes de tudo, acreditando na "inexistência de verdades universais e eternas". Todas as entrevistas foram gravadas e transcritas.

\section{Resultados}

O PSF legal

Paim ${ }^{11}$ define como SUS legal aquele desenhado pela Constituição Federal, e utilizamos também essa denominação para demonstrar como o PSF foi idealizado nas leis e portarias do SUS.

O Plano Operacional para 1994 do Ministério da Saúde identifica o Programa de Saúde da Família como capaz de "restaurar a dignidade dos profissionais de saúde, confiando que a partir disso se estabeleça o compromisso ético e que se forme um vínculo de confiança com a comu-

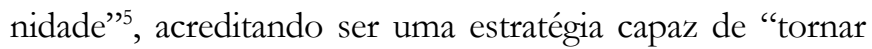
realidade os princípios básicos do SUS" . Para atingir esses objetivos determina que a unidade básica deva ser a "base de acesso ao sistema de saúde" ${ }^{5}$, constituindo o que chama "porta de entrada", sendo "essencial que se garanta o sistema de referência e contra-referência", enfatiza a importância da preparação de profissionais "capazes no exercício da cidadania, além de tecnicamente competentes"

Este plano norteou todo o processo de implantação do PSF de Juiz de Fora.

O Plano Municipal de Saúde (PMS) de 1997 usou como pano de fundo o diagnóstico realizado pelo Plano Estratégico de Juiz de Fora e teve dentre os seus focos a necessidade de ampliação da rede assistencial do SUS a partir da identificação de vazios assistenciais na Atenção Básica e da necessidade de suporte assistencial para o nível especializado além da adequação quali-quantitativa dos recursos humanos em saúde e da programação em todos os níveis do sistema priorizando a referência e contra-referência ${ }^{7}$.

$\mathrm{Na}$ análise do modelo assistencial, constatou-se que o acesso aos serviços era dificultado, o sistema de referência era precário, com um "número excessivo de encaminhamentos" para os institutos, e que a contra-referência não existia, principalmente pela ausência de prontuários nas clínicas especializadas. Também foi detectado e considerado um problema o fato dos usuários poderem marcar consultas especializadas sem o encaminhamento da unidade básica de saúde ${ }^{7}$, o que descaracterizava a UBS como "porta de entrada" do Sistema de Saúde. 
Uma das propostas do PMS-97 foi a organização de um sistema de referência e contra-referência suportado pelo prontuário de cada usuário. Considerava-se também que as equipes do PSF teriam

[...] supervisão contínua e permanente, sendo treinadas para utilização correta do sistema e atualização das informações, além do acompanhamento dos pacientes em nivel primário, no âmbito de sua capacidade, com a orientação de condutas recomendadas pelo nivel secundário?.

A III Conferência Municipal de Saúde (CMS) em 2000 trouxe novamente à baila essas discussões, e entre suas propostas tinha a criação de um departamento de Atenção Primária à Saúde, investimento prioritário na UBS e revisão do organograma adequando-o às "novas necessidades do modelo assistencial, além de garantir a efetividade das unidades de apoio"

A Reforma Administrativa de 2001 modificou o organograma, criou o Departamento de Atenção Primária à Saúde e redefiniu responsabilidades, porém, ao dar os primeiros passos na execução de suas reformas, aconteceram novas mudanças administrativas locais, frustrando os resultados esperados.

O Ministério da Saúde, por meio da Portaria 648/ GM de março 2006, aprovou a Política Nacional de Atenção Básica, estabeleceu diretrizes para o PSF e PACS, definindo responsabilidades de cada esfera de governo, adequando a infra-estrutura e recursos necessários com discriminação das atribuições de cada membro da equipe ${ }^{6}$.

A partir da análise desses documentos, percebemos a existência, em nível local e federal, de legislação suficiente para fazer com que a Saúde da Família funcione e faça valer os princípios do SUS e procuramos identificar nas falas dos usuários os desafios a serem vencidos para que isso aconteça.

\section{Percepção do usuário}

Como a pesquisa foi realizada com aqueles que freqüentavam a unidade com a estratégia de Saúde da Família, ficam mais evidentes as manifestações de apoio, porém, percebemos também algumas críticas ao atendimento local.
Faltam recursos, existem falhas na organização, falta integração e ainda existe dicotomia entre o SUS e o PSF

Consideramos como recursos os bens e serviços diretamente ligados à saúde e necessários para que se possa realizar um atendimento digno ao usuário, permitindo, não apenas sua inserção no Sistema de Saúde, mas também a resolubilidade, isto é, a resposta a todas as suas demandas. Falhas na organização seriam responsáveis pela má distribuição desses recursos nas unidades prestadoras de serviços ao público, refletindo-se nas falas dos usuários:

Aqui, os médicos são maravilhosos, só deixa a desejar a falta de remédios. Outra dificuldade da unidade é a falta de insumos, faltam materiais de curativo.

Em algumas falas percebemos críticas em relação aos recursos humanos especializados.

... Quando a gente chega pra consulta com o especialista, estava marcado pra 7 horas, mas ele só chega às 9 horas. Às vezes demora mesmo quando o médico chega cedo, ai o que vale é quem chegou primeiro. Acho que o horário deveria ser reservado.

"Quando precisa tem que vir bem cedinho e esperar"

Outra dificuldade percebida é a fila para a marcação de consultas, muito acima da capacidade de absorção da equipe, o que muitas vezes não permite o atendimento naquele horário. Como o paciente percebe que o atendimento do PSF é diferente, identifica o atendimento nas unidades especializadas como sendo SUS, criando uma dicotomia entre o SUS e o PSF.

Se não tivesse aqui, tinha que ir ao SUS. É bem longe e difícil de marcar.

Quando tenho algum problema venho no posto, mas, se não conseguir, vou direto ao SUS.

A gente tem que marcar uma consulta com o especialista do SUS só pra pedir um exame. Tinha que poder pedir aqui [na própria unidade], isso já adiantava o tratamento.

A marcação pela CMC [Central de Marcação de Consultas] demora bastante, às vezes não dá pra esperar.

Assim, o usuário, muitas vezes, procura direto uma unidade de urgência e cria uma imagem confusa do PSF.

Não tem facilidade de ser atendido fora do dia. Consulto 
muito na Unidade Regional (Unidade de urgência e emergência).

Para melhorar, acho que precisava ter garantia de consulta a qualquer hora.

Acho que aqui tinha que ter um Pronto Atendimento ou Emergência.

Tem gente que não precisa, mas vem consultar-se, tirando a vez de quem precisa.

A solicitação de exames é uma necessidade em muitas doenças, principalmente as crônicas, e os próprios pacientes, hoje, induzidos pela mídia ou por outros tipos de informações, buscam periodicamente as unidades para realizá-los. É o que chamam de check-up. Em suas falas, percebemos que há um descontentamento em relação à falta do acesso a exames, principalmente aqueles mais especializados, e também da falta de alguns equipamentos nas unidades, o que os faz desvalorizar o atendimento básico.

\section{Aqui não tem nem RX.}

Quando vou a Unidade Regional faço tudo o que preciso inclusive os exames sem ter que esperar. Aqui, além de demorar, temos que remarcar a consulta.

Fui ao endocrinologista, e ele me pediu uns exames, mas não consigo fazer. A moça ficou com o papel e disse que me ligava quando fosse marcado, mas isso já faz seis meses.

Muitas vezes, o usuário prefere procurar outros serviços ou os laboratórios particulares, e muitos laboratórios de bairros fazem "preço especial" para quem leva a solicitação do SUS, em uma competição positiva, uma vez que reduz a fila de espera, mas nem sempre isso é possível.

Se for esperar pelos exames, a gente morre. Eu prefiro pagar. É mais rápido e garantido.

Quanto à organização dos serviços, o usuário percebe que "algo não funciona bem", que faltam materiais, que faltam vagas especializadas, que o profissional não tem boa vontade, e, por isso, existe a demora, mas alguns pacientes deixam claro que possuem alternativas para "furar" o bloqueio em relação a consultas especializadas, procurando mecanismos para serem atendidos mais rapidamente. O Hospital Universitário é uma das opções, mas seu acesso depende também de uma indicação. Outra opção é a unidade de urgência que atende sem prontuário e apenas por demanda. Alguns recorrem ao pronto atendimento dos Planos de Saúde.

Às vezes, vou ao Regional, quando aqui está fechado, demora, mas consigo me consultar no mesmo dia.

Quando precisei de exames, demorou, tive dificuldade. Não tinha vaga. Tive que repetir o exame porque o primeiro não deu certo e aí procurei o HU [Hospital Universitário] e ficou mais fácil, mas tive que ir ao coordenadorpra conseguir uma vaga.

Tinha um plano do Sindicato, mas passei mal e fui direto ao Hospital Universitário. Foi de graça e não demorou nada. Vou direto à Associação dos Cegos. Marca direto e não demora nada.

Tenho um conhecido que marca direto no HU. Não demora nada.

Uma outra forma de conseguir o atendimento mais rápido seria por meio de planos de saúde. Alguns usuários que não os possuem declaram ser esse seu sonho de consumo, ou se percebe certo descontentamento com o serviço oferecido ou com o custo.

Acho que quem tem um bom plano de saúde não precisa esperar. À vezes tem um plano, mas que não cobre exames; aí, não adianta.

Meu Plano? É um SUS “arrumadinho", se precisar de um exame mais sofisticado tenho que pagar ou fazer no SUS.

Tenho o plano da AME. Só dá direito à consulta.

Dá direito a duas consultas por mês e desconto nos exames.

Tenho Plano de Saúde para internação, mas não pra consulta. Tenho que pagar os exames, a não ser quando internada.

Algumas vezes, o relato do usuário demonstra que, mesmo pagando um plano, ele já viveu a experiência de precisar e ter de recorrer ao SUS.

Senti-me mal, fui ao Regional Leste, e o cardiologista mandou direto pro hospital, o plano não cobria, fiz tudo pelo SUS.

Esses relatos demonstram a dificuldade do usuário, mesmo depois de cadastrados na unidade básica, conseguir o atendimento em serviços especializados e, em alguns casos, até mesmo o atendimento básico, uma vez que 
não existe uma comunicação efetiva entre os serviços.

\section{Existe uma rede de serviços em Juiz de Fora?}

O processo de descentralização tem possibilitado aos municípios criarem formas de organização das práticas de assistência à saúde com uma diversidade de modelos orientados pela integralidade, resolubilidade e acesso universal, instrumentalizadas pela saúde coletiva e pela clínica, mais próximas da realidade local ${ }^{13}$.

A prática, porém, não funciona em sintonia com a teoria, e, quando observamos a atuação em nível local, percebemos que se "torna urgente avaliar os diferentes impactos e promover a busca de alternativas para a construção de uma agenda que contribua para a equidade nas condições de vida e de saúde, consoante as diretrizes de um Sistema Único de Saúde"

Ao ser implantada, em 1995, a Central de Marcação de Consultas pretendia orientar o usuário, principalmente em relação aos mecanismos de referência e contrareferência, criando um fluxo entre os serviços. No início, chegou a funcionar, porém, com o crescimento da oferta, ocorreu uma ampliação do território de abrangência da saúde de Juiz de Fora, que passou a atuar como Município Pólo estabelecendo pactos para atendimento de outros municípios em consultas especializadas, por meio da Programação Pactuada Integrada (PPI).

Os territórios são "espaços de responsabilização sanitária" e, em se cumprindo os princípios da cooperação gerenciada, com definições claras das ações oferecidas por cada território às populações adscritas, haveria uma compatibilização na construção de uma rede de atenção à saúde com responsabilidades inequívocas ${ }^{14}$.

A ampliação do acesso, porém, sem a devida transparência na definição das competências e responsabilidades, gera um aumento na procura das unidades de atenção especializada (nível secundário), que atendem à demanda dos outros municípios e da população de Juiz de Fora das áreas descobertas pela Atenção Primária, construindo uma confusa malha de idas e vindas em busca do atendimento de médio e alto custo/complexidade.
Ao encaminhar o paciente para um nível de maior complexidade tecnológica, o médico entrega o encaminhamento ao paciente, que leva ao telefonista da UBS. Este entra em contato com a Central de Marcação de Consultas (CMC), por telefone, e solicita o agendamento da consulta especializada.

No nível central, o profissional da CMC rastreia na agenda dos especialistas disponíveis no sistema e, se existe a vaga, esta é reservada e repassada a informação para a unidade. A guia é devidamente preenchida com data, hora e nome do médico especialista de referência e, em seguida, é devolvida ao paciente. Se não existe a vaga no momento, a guia fica com a telefonista da UBS, que continua a tentar, toda manhã, quando abrem as agendas dos especialistas. Parece simples e deveria ser resolutivo, porém, esta marcação pode demorar meses.

A procura pelo especialista em Juiz de Fora é muito grande, pois os modelos assistenciais existentes até a década de 1990, que valorizavam as especialidades e as tecnologias utilizadas para diagnóstico, ainda estão presentes nos ideários dos pacientes e até de muitos profissionais de saúde. Além disso, para a solicitação dos exames complementares mais complexos, o paciente precisa ser encaminhado ao especialista para que ele faça a solicitação, aumentando a demanda e postergando o tratamento.

Quando ocorre uma situação de urgência, a guia de referência é entregue ao gerente da unidade, que liga para a coordenação de turno das unidades especializadas e marca na agenda do especialista em questão. O coordenador de turno guarda, diariamente, duas vagas, que são oferecidas nessas situações, para cada especialista ${ }^{15}$.

Em 2005, apenas das consultas para a cardiologia, 3.548 foram agendadas como urgentes, o que representou $13,9 \%$ das realizadas; para a endocrinologia, foram 1.983, representando $13,4 \%$ das realizadas e, para oftalmologia, foram $3.740,14,2 \%$, porém, na oftalmologia, estão inclúdas as consultas de retorno para procedimentos específicos, como curativos e avaliação pós-cirúrgica. Das consultas realizadas, 6.953 foram "urgências", representando $17,29 \%{ }^{15}$. 
Consideramos nesse cálculo apenas as consultas realizadas de fato, pois, cerca de $20 \%$ das agendadas são perdidas, isto é, os pacientes não comparecem nem avisam a tempo de serem substituídas, o que representa uma perda importante.

Apesar dos números e das consultas oferecidas e perdidas, quando tentamos responder a questão sobre se teríamos ou não uma rede de serviços, a resposta que nos vem é que não existe. Percebemos claramente uma divisão na qual, de um lado, temos a Central de Marcação de Consultas ligando a Atenção Primária aos Ambulatórios Especializados e, de outro lado, temos as Unidades de Urgência e Emergência ligados ao hospital pela Central de Vagas, porém, sem haver um relacionamento entre os dois lados, a não ser informalmente.

Essa falha na comunicação é percebida e utilizada pelos usuários, o que provoca um custo adicional, pois aqueles que possuem algumas informações privilegiadas ou facilidades por terem conhecidos ligados aos serviços, repetem vários procedimentos, muitas vezes desnecessariamente, onerando o sistema e dificultando a entrada de outros, menos informados.

\section{Discussão}

Analisar ações de saúde representa sempre um desafio, pois não existe um padrão de atendimento ou uma única maneira para se demonstrar satisfação ao ser atendido. Cada pessoa é única e assim são os seus sentimentos de aceitação ou negação de um determinado procedimento. Este sentimento muda também com o passar do tempo e com as novas experiências vividas.

Assim a abordagem qualitativa apresenta-se como orientação cada vez mais difundida no campo da atividade científica em todas as áreas do saber, em particular na saúde, que, pela sua complexidade e multidimensionalidade pede um desenvolvimento mais intenso do componente humano, domínio dos estudos qualitativos ${ }^{9}$.

Procuramos nesta análise muito mais que uma avaliação dos serviços, buscando entender o que os entrevistados diziam, "por trás do discurso aparente", conside- rando o impacto da organização dos serviços sobre a doença e os custos de seu manejo, e procurando entender de que forma são afetados (de forma negativa ou positiva) os outros aspectos da atenção ao paciente, aqueles de ordem biológica, psicológica, ambiental e principalmente de ordem social.

\section{Organização, integração e dicotomia entre o SUS e o PSF}

Nas respostas dos usuários, percebemos que as questões do acesso ainda não estão resolvidas, que existe um hiato na comunicação entre os serviços e falhas nas informações, o que se reflete nas reivindicações quanto ao funcionamento das unidades básicas.

Para promover a integração dos saberes, é necessário que essas questões sejam trazidas para as reuniões de equipe e conselhos e, em vez de se levantar trincheiras, que se traga esses ítens para o diálogo, oferecendo as informações necessárias aos Conselhos de Saúde e trabalhadores da ESF, construindo-se, no médio prazo, uma massa de pessoas esclarecidas trabalhando com um objetivo comum: o de promover a saúde nos diversos setores de trabalho e da sociedade, considerando-se que a produção da saúde local passa pelas relações estabelecidas entre os diversos atores administrativos, prestadores de serviços e usuários

Particularizando a questão do hipertenso inscrito nos grupos da ESF, seria interessante que a organização dos grupos respeitasse os interesses dos usuários e permitisse durante a troca de experiências o esclarecimento dos mecanismos de acesso aos serviços mais especializados, bem como o papel de cada serviço dentro do sistema de saúde, contribuindo para a disseminação da lógica da integralidade.

Dentre os serviços oferecidos pela ESF temos os grupos educativos e operativos, os atendimentos individuais com solicitação de exames considerados básicos e os encaminhamentos às especialidades, quando existe a necessidade de um procedimento mais específico. Se esta informação se fizer presente em todos os espaços do SUS, durante toda e qualquer ação executada, viabilizaria uma in- 
versão do modelo assistencial.

Assim, a transparência na divulgação das informações, associada à organização dos serviços, seria um grande passo na melhoria do acesso do usuário a qualquer nível de atenção que se fizesse necessário, possibilitando sua inclusão no sistema local.

Percebemos ainda uma grande dúvida entre o que é SUS e o que é PSF, não apenas por parte dos usuários, mas também por alguns profissionais. Esse assunto deveria ser exaustivamente discutido, clareando-se a idéia do PSF como estratégia de reorientação do SUS.

A logística dos serviços, mesmo quando não cita$\mathrm{da}$, permeou todos os depoimentos, da falta de vagas à falta de espaço físico adequado. Acreditamos que a descentralização da gestão, ocorrida na década de 1990, não sendo acompanhada de definições claras quanto às responsabilidades e competências, possa ser responsável por algumas dessas dificuldades, e percebemos nas entrevistas que existe uma grande distância entre quem recebe os serviços, quem executa as ações e quem planeja.

A organização dos conselhos contempla alguns destes objetivos, porém, é preciso que haja divulgação das decisões nas reuniões de Conselhos Locais de Saúde, permitindo maior envolvimento de todos os segmentos da sociedade ou que as reuniões do Conselho Municipal sejam itinerantes, acontecendo cada mês em um bairro, com ampla divulgação, permitindo a inserção social indiscriminada.

A realização do planejamento estratégico onde os diversos atores sociais têm voz e todos participam das tomadas de decisões, facilita a apropriação do processo, entendendo-se as dificuldades e lutando-se pelas melhorias com economia na utilização dos recursos disponíveis.

Importante enfatizar que não se pretende responsabilizar o usuário pelas questões ligadas a gestão, apenas oferecer informações que possibilitem a cobrança daqueles serviços por quem tem direito.

Nas questões ligadas à prática profissional consideramos algumas questões que foram relacionadas às falhas na formação ou no acompanhamento dos serviços.

As instituições de ensino ainda estão, com raras ex- ceções, direcionadas à formação de especialistas. No início da atividade clínica os médicos têm muitos sonhos. Mesmo os mais céticos, quando tomam contato com a ideologia da Medicina, encantam-se. Ao entrarem na rotina, porém, sentem-se, em um primeiro momento, perdidos, e, depois, decepcionados. Pouco se faz, pouco se ganha, sofre-se muito, com raras exceções. Quando falamos de ESF, fica um pouco pior, pois agregou-se às dificuldades da clínica às dos setores sociais e, muitas vezes, tem de se decidir sobre o que não se conhece.

Some-se a isso a demanda crescente e uma diversidade de formulários a serem preenchidos para atender aos diferentes Sistemas de Informação, e o que é pior, sequer se recebe as análises do preenchido, o que é uma contradição, já que esse material subsidiaria o planejamento local. Com tudo isso, incorporou-se tanta solicitação ao médico, que ele constrói sua prática dentro dos padrões que lhe permitam transitar sem muito sofrimento. É claro que alguma coisa fica por fazer. Cria-se uma cultura de exames e encaminhamentos. Ficam desanimados.

A redução do número de famílias da área de abrangência poderia diminuir demanda e daria uma folga para o planejamento e o trabalho coletivo como realmente deve ser no PSF. Atualmente, algumas equipes chegam a cobrir quatro mil pessoas, o que impede qualquer tipo de planejamento.

A educação continuada por meio da promoção de encontros entre generalistas e especialistas, em pequenos grupos, para debater problemas comuns que, sem dúvida, seriam de muita ajuda no cotidiano de generalistas e especialistas.

Entendemos também que, para que funcione a educação continuada, precisamos ter uma boa base na formação do profissional. Não se pode aprimorar o que nunca se teve. Essa é uma discussão que vem acontecendo já há algum tempo. As Diretrizes Curriculares de Curso de Medicina de 2001 enfatizam a necessidade de se formar generalistas com habilidades diversas e a importância da inserção precoce dos alunos nos cenários de práticas ${ }^{16}$.

$\mathrm{O}$ incentivo à participação em eventos científicos 
também é de grande valia na motivação do profissional, assim como uma relação mais estreita entre as instituições de ensino e os serviços básicos de saúde, em uma parceria ensino-serviço.

A prática diária dos serviços também deveria ser acompanhada mais de perto pelos supervisores, não para punir, mas para permitir um crescimento profissional e manter sempre atualizada a capacidade técnica do profissional, facilitando sua participação em cursos, treinamentos e até utilizando-se suas habilidades para desenvolver encontros de compartilhamento de experiências.

Enfim, as propostas são: estabelecer com as comunidades as parcerias, ouvir o colega em sua verdade, buscar nos livros as respostas e, principalmente, pensar na equipe como local de discussão e crescimento dos processos de trabalho e do planejamento de ações.

Assim, ao se orientar o fluxo a partir de propostas vindas das unidades básicas e de seus usuários, existiria a oportunidade de compartilhar responsabilidades. E, uma vez organizado esse fluxo nas unidades com ESF, outras unidades tenderiam a absorver as idéias e colocá-las em prática, favorecendo a melhorias no atendimento e na organização dos serviços.

Assim, a proposta desse estudo foi demonstrar, na opinião de usuários, alguns pontos críticos no funcionamento do PSF/SUS local; porém, não podemos nos furtar de oferecer, com base nas referências dos estudiosos do assunto, algumas idéias para buscar novos e melhores resultados.

Esperamos que esses resultados impulsionem outros estudos e que influenciem positivamente a saúde de Juiz de Fora e de outros municípios com realidades semelhantes.

\section{Referências}

1.Brasil. Ministério da Saúde. Leis Orgânicas da Saúde. n. $8080 / 1990$ e 8142/1990.

2.Starfield B. Atenção Primária: Equilíbrio entre as necessidades de saúde, serviços e tecnologia. Brasília (DF): UNESCO, Ministério da Saúde; 2002.
3.Mattos R. A integralidade na prática (ou sobre a prática) da integralidade. Cadernos de Saúde Pública 2004; 20(5): 1411-1416.

4.Organização Mundial de Saúde. Cuidados inovadores para condições crônicas: componentes estruturais de ação: relatório mundial. Disponível em: http://www.opas.org.br/ publicmo $>$, disponibilidade 12/3/2006

5.Brasil. Ministério da Saúde. Programa de saúde da Família - Plano Operacional para 1994. Brasília (DF): Ministério da Saúde; fev. 1994.

6.Brasil. Ministério da Saúde. Secretaria de Atenção à Saúde. Departamento de Atenção Básica. Política Nacional de Atenção Básica Brasília (DF): Ministério da Saúde; 2006. (Serie Pactos Pela Saúde, 4).

7.Prefeitura de Juiz de Fora, Secretaria de Saúde Saneamento e Desenvolvimento Ambiental, Plano Municipal de Saúde, 1997.

8.Minayo MCS. O desafio do Conhecimento: pesquisa qualitativa em saúde. 8 ed. São Paulo: Hucitec; 2004. 122p. 9.Bardin L. Análise de Conteúdo. França: Edições 70; 1977. 10.Bosi MLM, Mercado FJ (Orgs.). Pesquisa Qualitativa de Saúde. Petrópolis (RJ): Vozes; 2004.

11.Paim JS. Políticas de Descentralização e Atenção Primária à Saúde. In Rouquayrol MZ, Almeida Filho N. Epidemiologia e Saúde. 5 ed. Rio de Janeiro: MEDSI; 1999. p. $489-503$.

12. Juiz de Fora [Prefeitura]. Secretaria de Saúde Saneamento e Desenvolvimento Ambiental. III Conferência Municipal de Saúde: Relatório. Juiz de Fora: Secretaria de Saúde, Saneamento e Desenvolvimento; 2000.

13.Mendes EV, Pestana M. Pacto de Gestão: da municipalização autárquica regionalização cooperativa. Secretaria de Estado da Saúde de Minas Gerais, Belo Horizonte, 2004 Disponível em: http:http://www.saude.mg.gov.br/publicacoes/livros Acesso em: 12/03/2006.

14.Mendes EV. Os grandes dilemas do SUS, tomo II. Salvador (BA): Casa da Qualidade; 2001.

15. Juiz de Fora [Prefeitura]. Secretaria de Saúde Saneamento e Desenvolvimento Ambiental. Seção de Estatística do Departamento de Clínicas Especializadas, Dados Pri- 
mários sobre o atendimento ambulatorial, 2004- 2006. Juiz de Fora (MG): Secretaria de Saúde Saneamento e Desenvolvimento Ambiental; 2004.

16.Brasil. Ministério da Educação. Conselho Nacional de Educação - Câmara de Educação Superior - Diretrizes Curriculares Nacionais do Curso de Graduação em Medicina - 2001. Brasília (DF): Ministério da Educação; 2001.

\section{Endereço para correspondência:}

Avenida Barão do Rio Branco, 3596 - Apto. 2202

Centro - Juiz de Fora - MG

CEP: 36025-020

\section{Endereço eletrônico:}

celiasaldanha@yahoo.com.br 